\title{
Refractory Gallbladder Carcinoma
}

National Cancer Institute

\section{Source}

National Cancer Institute. Refractory Gallbladder Carcinoma. NCI Thesaurus. Code C162753.

Gallbladder carcinoma that is resistant to treatment. 